\title{
Analysis of Software Success Through Structural Equation Modeling
}

\author{
Muhammad Hamid ${ }^{1, *}$, Furkh Zeshan ${ }^{2}$, Adnan Ahmad ${ }^{2}$, Saadia Malik ${ }^{3}$, Muhammad Saleem ${ }^{4}$, \\ Nadia Tabassum ${ }^{5}$ and Muhammad Qasim ${ }^{1}$
}

\footnotetext{
${ }^{1}$ Department of Statistics \& Computer Science, University of Veterinary and Animal Sciences (UVAS), Lahore, 54000, Pakistan

${ }^{2}$ Department of Computer Science, COMSATS University Islamabad, Lahore Campus, Lahore, 54000, Pakistan

${ }^{3}$ Department of Information Systems, Faculty of Computing and Information Technology - Rabigh, King Abdulaziz University, Jeddah, 21589, Saudi Arabia

${ }^{4}$ Department of Industrial Engineering, Faculty of Engineering, Rabigh, King Abdulaziz University, Jeddah, 21589, Saudi Arabia

${ }^{5}$ Department of Computer Science, Virtual University of Pakistan, Lahore, 54000, Pakistan

*Corresponding Author: Muhammad Hamid. Email: Muhammad.hamid@uvas.edu.pk

Received: 13 June 2021; Accepted: 30 July 2021
}

\begin{abstract}
Determining factors influencing the success of software projects has been the emphasis of extensive research for more than 40 years. However, the majority of research in this domain has focused on developed countries, with little attention paid to underdeveloped and developing countries. The primary objective of this article was to assess the effect of critical elements on the success of software projects in underdeveloped countries (like Pakistan), because enterprise environmental factors and staff working habits, as well as their experience and expertise level, all have an effect on a project's success. For this purpose, data were collected from 339 senior developers and project managers working in Pakistan Software Export Board (PSEB) registered software companies. Structural Equation Modelling (SEM) was used to analyze the constructs and to assess the relationship between factors affecting software success. The empirical results showed that improper planning, inadequate human resources, wrong estimation of time and cost significantly negatively impacted the success of software projects. This research has opened new doors to extend our work in the software community to ultimately succeed in software projects.
\end{abstract}

Keywords: Cost estimation; human resource selection; software planning; software project management; software success; time estimation

\section{Introduction}

Software project development is a significant source of revenue for software companies all over the world. Successful completion of software projects has a positive impact on software exports, which promotes the economy of a country and creates new jobs. Successful software affects the software industry in terms of increased revenue, the development team in terms of reputation, the public in terms of job creation and the whole country in increased exports.

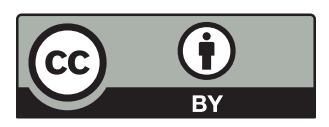

This work is licensed under a Creative Commons Attribution 4.0 International License, which permits unrestricted use, distribution, and reproduction in any medium, provided the original work is properly cited. 
In Asian countries, software project exports are growing every year, which is reflected by their contribution towards software project exports worldwide. Geographically, Pakistan is situated in a significant place in the region. It shares its borders with China, India, Afghanistan and Iran. Among them, China and India are the leading software exporter countries in the world. Although software exports of Pakistan are increasing every year; they are still far behind compared to her neighboring countries like India and China. For instance, in the fiscal year 2018-19, software exports of Pakistan were $\$ 5$ billion whereas, during the same time, software exports of India and China were \$137 billion and \$38 billion respectively [1].

Over the last few years, China and Pakistan have created strong joint trade and economic connections. The China-Pakistan Economic Corridor (CPEC) is further predicted to strengthen trade and economic collaboration between the two countries. Besides, contributing to trade and industrial development activities in Pakistan, an early focus on the software aspect of the CPEC project would also help in the information technology revolution in Pakistan. On the other hand, India and Pakistan share a similar culture and social values, but the software industry of Pakistan faces more problems and capital losses during software development compared to the Indian software industry. Along with the motivation to compete with her neighbors, little research initiatives were taken for the identification of critical factors reducing the success of software projects in Pakistan. Vrchota et al. [2] investigated that critical success factors vary by project types, incremental stages, businesses, nationalities, individuals and organizations.

Software project success requires a project to accomplish all specified features within the allocated time and budget. Two famous groups General Accounting Office GAO (established 1979) and Standish Group (established 1994) publish their reports every year regarding factors associated with software project success. According to their latest findings, the critical factors that contribute towards software project success are planning, human resources as well as estimation of time and cost. Moreover, according to literature planning, inadequate human resources, time and cost estimation are the most important factors because even after 50 years of research into software project management, failure factors are still limited to these four factors. In addition, according to the facts based on literature, $52.7 \%$ of projects were not able to complete at the scheduled time and within the cost, similarly, poor planning also plays an important role in the failure of the software project. According to the group's more recent report in 2019, even successful software projects need to work on how to improve software estimation. However, estimation of time and cost is complex because of cultural differences, working conditions, habits of developers or professionals. As a result, the primary goal of this research is to use a survey-based statistical study in Pakistan to quantify the impact of poor planning, inadequate human resources and improper time and cost estimates on the success of software projects.

The article organized as a fellow: Section 2 briefly presents some related research work and formulates the research hypothesis. Section 3 illustrates the statistical methodology and data collection procedure. Section 4 describes the analysis of the data and results while Section 5 concludes the article and potential future research directions. Section 6 presents the research contribution.

\section{Related Work}

According to the studies, there exist several factors that affect software projects negatively. Among, which the most influential are planning, cost, time and Human Resource (HR), because poor HR performance has a direct negative impact on cost and time. Therefore, in this section, an extensive review of literature is performed in these areas to explore how critical these factors are considered by the software industry of the developing countries. In this regards, we have divided the literature into four categories, namely: a) effect of project planning; b) effect of human resource; c) effect of time estimation; and d) effect of cost estimation. Following is a brief description of these four dimensions. 


\subsection{Effect of Project Planning}

In the software development industry, the probability that a project may attain a certain level of success depends on its planning phase. Muller et al. [3] conducted a survey of 78 software practitioners to identify critical success factors in software development. Their findings showed that proper planning was the main contributing factor for software project success. Also, as noted by Demir [4], improper planning during software development ultimately decreases the success of software projects. Likewise, Stylianou et al. [5] identified two main factors through a literature review that leads a software towards success, which include planning and time estimation. Similarly, Vasantrao et al. [6] identified through literature that early planning plays a vital role in the success of software projects. In addition, Attarzadeh et al. [7] developed a questionnaire to investigate the factors that contribute to software project success. Analysis of over 50 developers, who completed their projects, showed that better planning is the leading contributing factor in software success.

The above literature reflects that project planning is one of the contributing factors for the success of software projects, as, without proper planning, the requirements of a software project are hard to achieve. Considering similar constraints, various studies have proposed measures for proper software project planning which include: detailed written software development plan, architecture and design plan, quality assurance plan, staged delivery plan and third-party software integration plan [8].

\subsection{Effect of Human Resource}

Human Resource Management (HRM) is an important part of almost every organization to progressively sustain its strategic role in project success. Though, the empirical study results of Pinto and Prescott contradicted this trend and concluded that a marginal role of project success is played by "Personal factor", Belout et al. [9], tried to retest their conclusions by reconsidering issues of validity of the measures used in the former study. Their result showed that there is a close relationship between human personals and software project success.

On similar lines, various other studies, for example as conducted by Belout [10], examined the construct validity of the human resources factor. Both of these studies confirm a moderating effect between human resources and project success. Furthermore, Mohd et al. [11] conducted an empirical study to explore the reasons behind the success of a software project in Jordanian firms. Their findings revealed that the key factor was adequate and proper human resources during software development.

In addition, Jeet et al. [12] identified that the low productivity of IT professionals involved in the development process decreases the chances of project success. Likewise, Jin [13] conducted an empirical study of successful software projects in Dalian city and found that that the main reason for their success was quality IT skills professionals. Moreover, Dikert et al. [14] performed a systematic literature review on 52 articles and found that the most important factor in software project success is human resources. Further, they identified various reasons for software project success in different software development circumstances. His findings suggested that the key cause was appropriate selection and allocation of human resources during the development process.

An adequate software development team produces quality work, however, if the team members are not suitable, a lot of rework may be needed to finalize the project, which ultimately delays and over budget the software project. On the other hand, a suitable selection of team members has a positive impact on software quality and risk control and also enhances the satisfaction of team members which is directly proportional to software productivity. Along with the identification of HRM as an important aspect of project success, several studies have also proposed some measures for improved human resource management and includes technical expertise, executive management support, team's expertise in the business environment, the 
capability of the manager to lead the project successfully, optimized resource engagement in the project and commitment of people working together in a team.

\subsection{Effect of Time Estimation}

One of the parameters that declare projects as successful is their timely completion therefore, proper time estimation plays an important role in the success of a software project. Popli et al. [15] inspected the effect of time estimation practices and their inferences on software project success. The results showed that systems that can properly estimate the time for project completion can increase the probability of software success. Also, Cerpa et al. [16] developed a questionnaire after an extensive literature review and discussion with 90 software practitioners. The focus of their questionnaire was to explore the reasons that compromise software success. The questionnaire was distributed to software practitioners in three different countries including the U.S., Australia and Chilean. An analysis of 70 software projects showed that $81 \%$ of software projects failed due to poor time estimation.

Likewise, Falahah [17] conducted a case study in Indonesia using a SERIM method for identifying major factors influencing software success. The results determined that proper estimation of time during software development significantly contributes towards software success. Another empirical study conducted by Berntsson et al. [18] among IT practitioners of Sweden and Australia to identify major causes of software project failure. Their study identified that the most critical factor that reduces the success of a software project was the wrong estimation of the time. Further, Molokken et al. [19] explored the literature to summarizes the knowledge of project success or failure. Their findings reflected that most companies used the expert judgment for estimation and around $40 \%$ of software projects fail due to the wrong estimate of time.

In addition, Chow et al. [20] identified 12 factors that increase the chances of success of a software project and proper estimation of time was one of them. These results are confirmed by an empirical study [21] among 23 IT companies in Yugoslavia countries. The results indicated 36 factors that influence the software project success where time estimation was a vital factor. In another empirical study conducted by Verner et al. [22] for the identification of major factors that influence the project outcomes. They collected data of 235 projects from North Eastern USA and Australian IT companies, while their results showed that proper time estimation in the early stage of the software life cycle was an essential factor behind the success of software projects.

From the above literature, it is concluded that estimation of time has a positive impact on the outcome of software projects. Proper time estimation at an early stage of the software development lifecycle helps the project managers in resource allocation and management during development that ultimately increases the chance of software success.

\subsection{Impact of Cost Estimation}

Along with project planning, human resource management and time estimation, cost estimation is considered another important factor necessary for the success of a software project. Jorgensen et al. [23] conducted systematic literature in the context of software development. In a review of 304 research articles about successful software projects, their findings showed a key factor for software success is proper cost estimation. Likewise, Verner et al. [24] conducted a case study on software practitioners in the U.S. They designed a questionnaire after consulting the literature and discussing it with 21 senior software practitioners. Their analysis indicated that if project managers properly estimate the cost of a project at an initial stage, it can increase the chances of success. Similarly, Stankovic and colleagues conducted an empirical study in the Yugoslavia countries within South-Eastern Europe (SEE) region for identifying the critical influencing factors behind software project output. Their study results showed that 
better estimation of cost positively influences the success of software projects. In addition, Bin et al. [25] conducted a literature review and identified that the wrong estimation of cost negatively influences the software project's success. They further proposed an algorithm to predict the cost of a project based on historical data. Furthermore, Debari et al. [26] developed a method after critically analyzing the literature to reduce software project success. Their method was applied in Japan as a case study and results showed that the wrong estimation of cost reduces the probability of success of a software project.

The discussion above demonstrated that proper cost estimation is essential for successful projects. Cost estimation forecasts the resources and associated costs that will be required to complete a project, which assists project managers in achieving project objectives within the timeframe and budget constraints that have been established. According to the findings of the above literature review, proper planning, adequate human resource allocation and appropriate time and cost estimation, all contribute to the success of software projects in developed countries. According to the literature, there has been minimal research on the impact of planning, human resources, time and cost estimation on the success of software projects in Pakistan's software companies. The following are the research hypotheses for this study.

H1: Improper project planning will have a negative impact on software project success.

$\mathrm{H} 2$ : Inadequate human resources will have a negative impact on software project success.

H3: Poor estimation of time will have a negative impact on software project success.

H4: Poor estimation of the cost will have a negative impact on software project success.

\section{Research Methodology}

In this section, the strategy of data collection and sample of the study are discussed along with measurements of the variables.

\subsection{Data Collection Procedure}

For this study, various software companies, registered in Pakistan Software Export Board (PSEB), were targeted for the collection of data. The current study used cross-sectional and quantitative methods. The managing director of PSEB was approached to circulate the questionnaire among the registered companies in Pakistan. The managing director assigned the duty to the software project manager of PSEB to distribute the questionnaire among registered companies and follow up. The questionnaire was sent through email to all the registered companies. The software project manager distributed the questionnaire to 500 registered companies by using a simple random sampling technique where only 339 (approximately 68\% response rate) companies responded to the questionnaire. Data were analyzed by means of the Analysis of a Moment Structures (AMOS) and Statistical Packages for Social Sciences (SPSS V. 21), while Cronbach's Alpha $(\alpha)$ was used to calculate the reliability of all variables used in this research. Furthermore, Structural Equation Modelling (SEM) was analyzed to understand the construction of constructs and to assess the relationship among factors affecting software success.

\subsection{Measurement}

Multi-items measures were used to operationalize each variable. More specifically, the planning and human resource variables were measured with eight and six items, respectively. Similarly, the estimation of time and cost were measured with the help of five items each. Finally, ten items, adapted from were followed to determine the success of software projects. 


\section{Results and Discussion}

Before starting data analysis, the researcher should verify the accuracy of the collected data because it provides an explanation of the methods used and helps in proving the hypothesis. Therefore, in this section reliability analysis is performed along with the explanation of the descriptive findings of the survey.

\subsection{Descriptive Analysis}

Tab. 1 provides demographic information about respondents' job position, experience, organization levels, types of developed applications and software development process adapted during the last developed software project. It can be seen from Tab. 1 that the majority of the sample was composed of project managers (approximately 37\%). Similarly, maximum respondents had experience ranging from 5 to 10 years (approximately 43\%). Furthermore, it is evident from the results that CMMI levels 3 and 4 were present in the majority of the sample (approximately $22 \%$ and $25 \%$, respectively). It can also be observed that web-based companies (approximately 33\%) and E-Commerce (approximately 29\%) had taken a major contribution to the local software industry. Finally, it was observed that most of the organizations used scrum technology in software development which made $33 \%$ of the total sample.

Table 1: Demographic characteristics of the respondents

\begin{tabular}{|c|c|c|c|}
\hline Variables & Frequency & Percent & Cumulative Percent \\
\hline \multicolumn{4}{|l|}{ Position } \\
\hline Architect & 24 & 7.08 & 7.08 \\
\hline Business Analyst & 24 & 7.08 & 14.16 \\
\hline IT Director & 24 & 7.08 & 21.24 \\
\hline IT Manager & 57 & 16.81 & 38.05 \\
\hline Project Manager & 125 & 36.87 & 74.93 \\
\hline Product Owner & 46 & 13.57 & 88.50 \\
\hline Programmer & 15 & 4.42 & 92.92 \\
\hline QA Engineer & 24 & 7.08 & 100.00 \\
\hline \multicolumn{4}{|l|}{ Experience } \\
\hline Less than 2 Years & 50 & 14.75 & 14.75 \\
\hline Between 2 to 5 Years & 57 & 16.81 & 31.56 \\
\hline Between 5 to 10 Years & 147 & 43.36 & 74.93 \\
\hline Between 10 to 20 Years & 85 & 25.07 & 100.00 \\
\hline \multicolumn{4}{|l|}{ Organization Level } \\
\hline CMMI Level 1 & 28 & 8.26 & 8.26 \\
\hline CMMI Level 2 & 65 & 19.17 & 27.43 \\
\hline CMMI Level 3 & 73 & 21.53 & 48.97 \\
\hline CMMI Level 4 & 86 & 25.37 & 74.34 \\
\hline CMMI Level 5 & 62 & 18.29 & 92.63 \\
\hline ISO 9000 Standard & 20 & 5.90 & 98.53 \\
\hline ISO 12207 Standard & 1 & 0.29 & 98.82 \\
\hline ISO 15288 Standard & 4 & 1.18 & 100.00 \\
\hline
\end{tabular}




\begin{tabular}{llll}
\hline Table 1 (continued) & & & \\
\hline Variables & Frequency & Percent & Cumulative Percent \\
\hline Type of Organization & & & \\
E-Commerce & 99 & 29.20 & 29.20 \\
Government & 48 & 14.16 & 43.36 \\
Mobile Application & 57 & 16.81 & 60.18 \\
Real-time system & 24 & 7.08 & 67.26 \\
Web Based & 111 & 32.74 & 100.00 \\
Software Development Process & & & \\
Feature Driven Development & 42 & 12.39 & 12.39 \\
Rapid Application Development & 47 & 13.86 & 26.25 \\
Scrum & 112 & 33.04 & 59.29 \\
Spiral Model & 36 & 10.62 & 69.91 \\
Waterfall & 47 & 13.86 & 83.78 \\
XP & 52 & 15.34 & 99.12 \\
V-Model & 3 & 0.88 & 100.00 \\
Total & 339 & & \\
\hline
\end{tabular}

\subsection{Reliability Analysis}

The reliability of the factors was calculated through Cronbach's alpha $(\alpha)$. A variable is considered reliable if the value of Cronbach's alpha $\alpha>0.70$. The study variables of time estimation and cost estimation had five items each and their reliability was $\alpha=0.95$ and $\alpha=0.72$ respectively. The human resource variable had six items with $\alpha=0.86$; planning had an eight-item with $\alpha=0.75$ while success had ten items with $\alpha=0.80$.

\subsection{Structural Equation Modelling (SEM)}

Nowadays, SEM is considered the most popular statistical technique to analyze factors with multi-items pertaining to study variables. It is used to judge the unobservable latent constructs by invoking a measurement model that defines the latent variables through multiple observed variables and imputes the relationship between latent variables. For analysis using SEM, different codes were used to represent the study variables, for example, planning was coded as "P_LAN" with items from P1 to P8, the human resource was coded as "HUM" with items from $\mathrm{H} 1$ to $\mathrm{H} \overline{6}$, time estimation was coded as "T_IME" with items from T1 to T5 and cost estimation was coded as "C_OST" with items from C1 to C5.

Confirmatory Factor Analysis (CFA). CFA was used to analyze the construct validity and is considered the first step in SEM. Moreover, convergent and discriminant validity are the two most important types of validities, which are applied to assess the validity and finalization of study constructs.

Measurement Model. The first step in CFA is the development and evaluation of the measurement model. During the development of measurement, items S8, S9, S10 and P4 were deleted due to factor loading issues. After the finalization of the measurement model, it was assessed through normed Chisquare $\left(\chi^{2}\right)$, Comparative Fit Index (CFI), Non-normed Fit Index (NNFI) and Root Means Square Error (RMSE). The $\chi^{2}$ index is analyzed by dividing $\chi^{2}$ on its degrees of freedom (df), where a smaller value 
of $\chi^{2}(<3)$ shows a better fit and vice versa. Tab. 2 indicates that the measurement model is well fitted because of the value of normed

$\chi^{2}<3\left(\chi^{2}=554.411, \mathrm{df}=393, \frac{\chi^{2}}{\mathrm{df}}=1.41\right)$

Table 2: Goodness of fit of the measurement model

\begin{tabular}{llllll}
\hline$\chi^{2}$ & df & $\frac{\chi^{2}}{\text { df }}$ & CFI & NNFI & RMSE \\
\hline 554.411 & 393 & $1.411<3.00$ & $0.971 \geq 0.90$ & $0.968 \geq 0.90$ & $0.035<0.08$ \\
\hline
\end{tabular}

Further, both CFI and NNFI are used to measure the goodness of fit of a measurement model. Cheung et al. [27] suggested that the value of CFI and NNFI should be greater than or equal to 0.90. Results show that the model is a better fit as the values of CFI and NNFI are 0.971 and 0.968 , respectively. Likewise, RMSE is another criteria to judge the goodness of fit of the model with a recommended threshold value of less than 0.08. Results show that the model is a better fit as the value of RMSE is 0.035 . Therefore, based on the results of $\chi^{2}$, CFI, NNFI and RMSE, it is concluded that the measurement model is well fitted in the current study.

Convergent Validity. The construct validity defines the degree to which inferences can justifiably be drawn from the operationalizations in a study to the theoretical constructs on which those operationalizations were founded. Two important subtypes of construct validity are convergent validity and discriminant validity. Convergent validity defines the degree where two measures of construct relate to each other and are assessed through standardized factor loadings, Average Variance Extracted (AVE) and Composite Reliability (CR). Asparouhov et al. [28] suggested that each standardized factor loading should be greater than 0.40 for good validity, whereas, the value of AVE and CR should be greater than 0.50 and 0.70 , respectively.

The results of CR and AVE are given in Tab. 3, which indicates that the value of factor loadings for each variable is greater than 0.40 . Similarly, the AVE value of each variable is greater than 0.50 which shows that convergent validity is satisfied. Furthermore, the $C R$ value of each construct is greater than 0.70 which shows that convergent validity is satisfied. Based on the standardized factor loadings, CR and AVE results, it is concluded that overall convergent validity is satisfied. Fig. 1 displays the measurement model interaction.

Table 3: Goodness of fit of the measurement model

\begin{tabular}{llllll}
\hline Convergent Validities & Planning & HR & Time & Cost & Success \\
\hline CR & 0.796 & 0.883 & 0.948 & 0.724 & 0.906 \\
AVE & 0.400 & 0.557 & 0.783 & 0.400 & 0.572 \\
\hline
\end{tabular}

Fig. 1 displays the measurement model reflecting the relationship among factors built-in AMOS. The circles and squares define the error terms and observed variables, respectively. This model comprises five factors, where the value of standardized factor loading for each variable is greater than 0.40. Major findings from Fig. 1 can be summarized as:

- It can be observed that the planning factor is positively associated with human resource and software success while negatively associated with time and cost factors. Therefore, proper planning would 
result in better human resources while simultaneously reducing cost and time, which could result in a successful project.

- Moreover, the human resource factor is positively associated with software success and negatively associated with cost and time. This implies that adequate human resources will reduce the time and cost spent on a project, potentially resulting in a successful project.

- Similarly, the time factor is positively associated with the cost factor while negatively associated with software success. This suggests that increased time will result in increased cost, which may lead the software to fail.

- Finally, the cost factor is negatively associated with software success. This suggests that increased costs will result in software failure.

Discriminant Validity. The main aim of discriminant validity is to define a construct that is completely different from other constructs. According to researchers, discriminant validity is determined by comparing the square root of AVE with the correlation between variables. Specifically, according to Ziat and colleagues, discriminant validity is satisfied when the square root of the AVE is greater than the correlation between the pair of latent variables. The results of discriminant validity are compiled in Tab. 4 with the square root of AVE on the diagonal, which shows that discriminant validity is satisfied as the square roots of AVEs are greater than the correlation between latent variables.

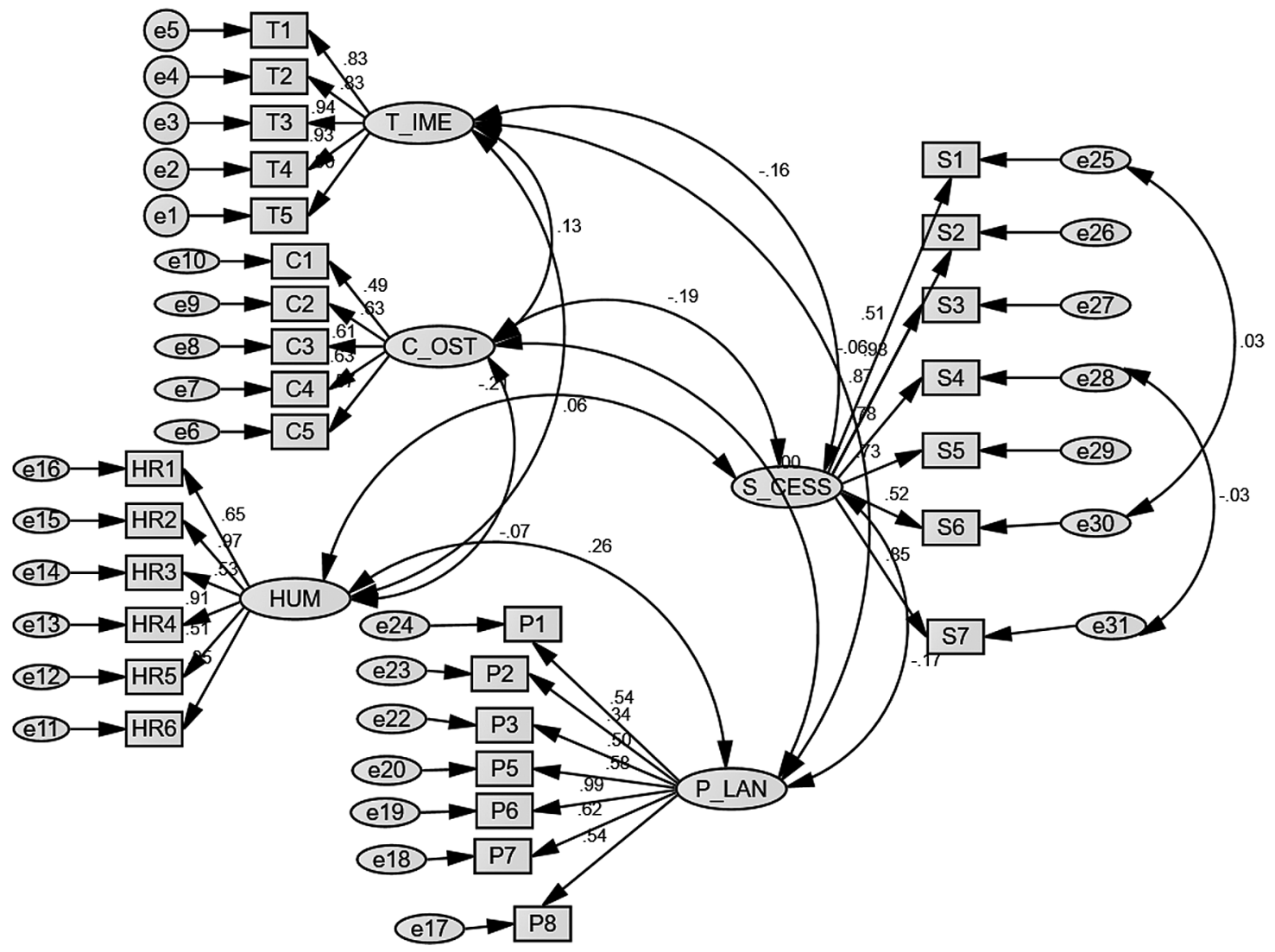

Figure 1: Measurement model 
Table 4: Discriminant validity matrix

\begin{tabular}{llllll}
\hline Variables & 1 & 2 & 3 & 4 & 5 \\
\hline 1. Planning & $\mathbf{0 . 6 3 2}$ & & & & \\
2. Human Resource & $0.258^{* *}$ & $\mathbf{0 . 7 4 6}$ & & & \\
3. Estimation of Time & -0.048 & 0.057 & $\mathbf{0 . 8 8 5}$ & & \\
4. Estimation of Cost & -0.033 & -0.085 & $0.111^{*}$ & $\mathbf{0 . 6 3 2}$ & \\
5. Success & $-0.216^{* *}$ & $-0.204^{* *}$ & $-0.151^{* *}$ & $-0.126^{*}$ & $\mathbf{0 . 7 6 7}$ \\
\hline Notes: **Significant correlation when $(p<0.01)$; Significant correlation when $(p<0.05)$ & &
\end{tabular}

\subsection{The Structural Equation Model Analysis}

The structural relationship was analyzed by means of SEM which is considered a multivariate technique. Moreover, it can be used to estimate the unobservable latent constructs by invoking a measurement model that describes the latent variables through multiple observed variables and imputes the relationship between latent variables. The model fitness criteria show that the measurement model is well fitted. So, the relationship among factors affecting software project success was checked. The effect of different factors including time, planning, human resource and cost on success is determined through SEM. It has been observed that poor planning, a lack of human resources and improper time and cost estimates have all had a negative impact on the success of software development projects. The result of hypotheses testing obtained from SEM is given in Tab. 5. The factors which were estimated by SEM are also shown in Fig. 2 where improper planning, inadequate human resource, poor estimation of time and cost have a significant negative impact on software success.

Table 5: Hypotheses testing

\begin{tabular}{lllll}
\hline Hypothesis & Coefficients $(\beta)$ & SE & t-statistic & p-value \\
\hline P_LAN -> Success & -0.095 & 0.040 & -2.369 & 0.018 \\
HUM -> Success & -0.095 & 0.030 & -3.171 & 0.002 \\
T_IME-> Success & -0.052 & 0.020 & -2.578 & 0.010 \\
C_OST -> Success & -0.128 & 0.045 & -2.822 & 0.005 \\
\hline
\end{tabular}

The findings from the analysis of the model are summarized below:

1. The findings show that improper planning has a statistically significant negative effect on software development success $(\beta=-0.095 ; \mathrm{t}=-2.369$; $\mathrm{p}$-value $<0.018)$, which supports the hypothesis $H_{1}$.

2. Additionally, the model demonstrates that inadequate human resources negatively impacts on the success of software development $(\beta=-0.095 ; \mathrm{t}=-3.171$; $\mathrm{p}$-value $<0.002)$, which completely supports the hypothesis $\mathrm{H}_{2}$. Despite the fact that a high-quality software development team produces high-quality work, if the team members are not suitable for the job, extensive rework may be required to complete the project, resulting in the project being delayed and overbudget. A suitable selection of team members, on the other hand, has a positive impact on software quality and also implies the satisfaction of team members, both of which are directly proportional to the overall productivity of the software product.

3. Moreover, it can be observed that a poor estimation of time has a negative and significant impact on the success of a software project $(\beta=-0.052 ; \mathrm{t}=-2.578 ; \mathrm{p}$-value $<0.010)$, which supports the 
hypothesis $H_{3}$. As a result, inaccurate time estimation had a statistically significant negative impact on the success of a software project.

4. Finally, the model reflects that poor cost estimation has a statistically significant negative impact on the success of software development $(\beta=-0.128 ; \mathrm{t}=-2.822$; $\mathrm{p}$-value $<0.005)$, which completely supports the hypothesis $H_{4}$.

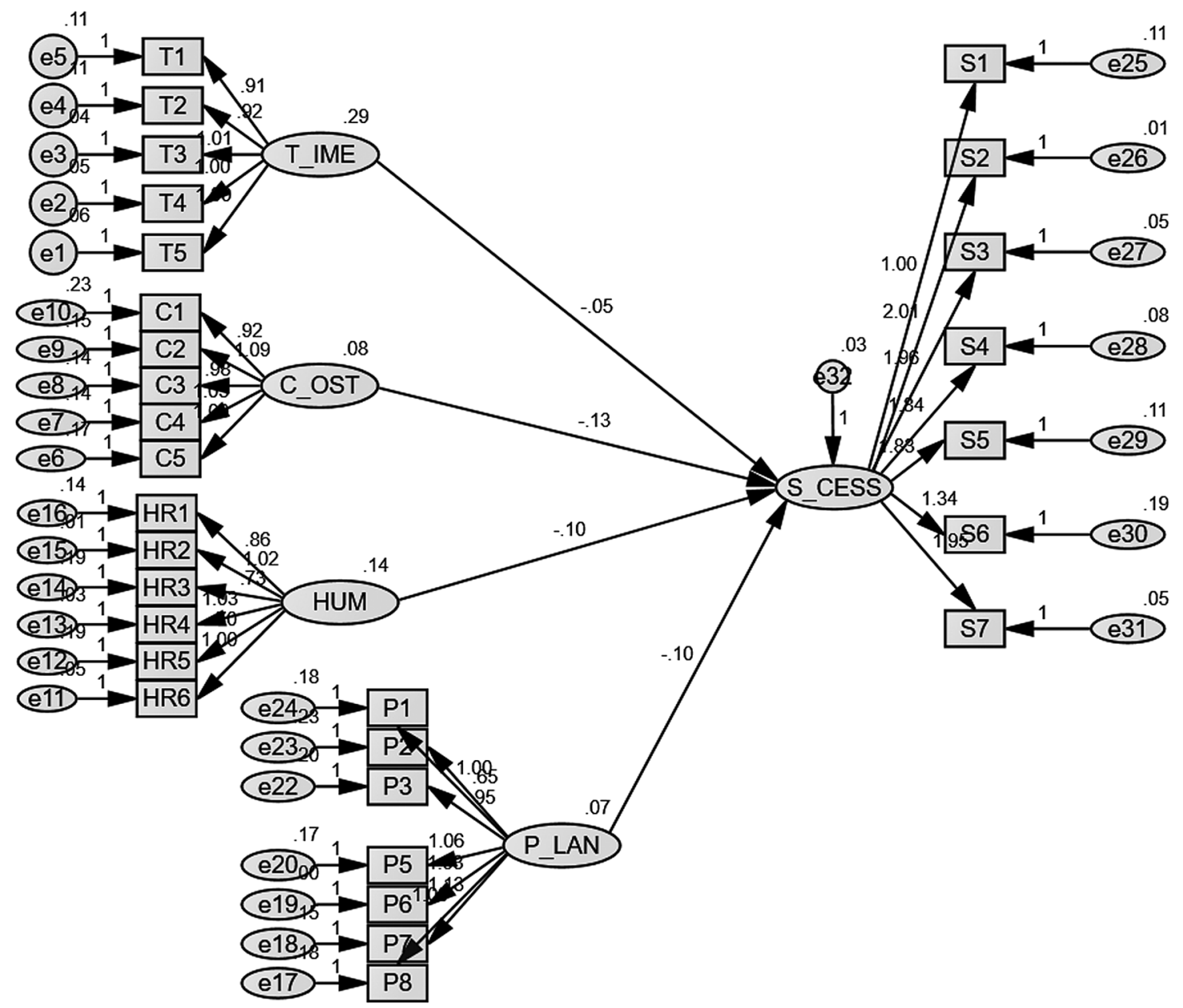

Figure 2: Structural model

\section{Conclusion}

The primary objective of this article was to observe the impact of improper planning, inadequate human resource and wrong estimation of time and cost factors on software project success. Simple random sampling was used to collect data from 339 senior developers and project managers employed by PSEB-registered software companies. Analyses of the proposed hypotheses were conducted using the SEM. According to the empirical findings of this study, wrong planning, inadequate human resources and improper time and cost estimation have a significant negative impact on software success. During software development, understanding and monitoring these essential aspects increase the probability of success. Successfully completion of software projects has a positive impact on software exports, which not only enhances the economy of the country but also creates new jobs. 
When interpreting these findings, it is important to keep certain limitations in mind. The data used in the current study came from software companies that were registered with the PSEB. The results of this study may differ in other unregistered software companies and other geographical sectors than in this study. As a result, future studies should concentrate on companies and other regions that have not yet registered as well as other geographically disparate software development projects in order to determine the impact of planning, human resource, cost and time estimation factors on software development projects success in the future. A future study might be conducted by using other factors, such as security, executive management support, clear requirement, knowledge sharing, scope and quality factors, etc.

\section{Research Contribution}

Discussion through experts and after extensive literature review, a questionnaire was developed for the identification of critical success factors in third world countries like Pakistan. The data was collected from PSEB registered software companies and evaluated the existing procedure for software project management and the decision-making process. The results showed that improper planning, inadequate human resources, wrong estimation of time and cost were major influencing factors towards software success in Pakistan.

Acknowledgement: We are grateful to our families and colleagues who have offered moral support throughout this process.

Funding Statement: The authors did not receive any specific funding for this research.

Conflicts of Interest: The authors declare that they have no conflicts of interest to report regarding the present study.

\section{References}

[1] W. Zhang and T. A. Neyazi, "Communication and technology theories from the South: The cases of China and India," Annals of the Int. Communication Association, vol. 44, no. 1, pp. 34-49, 2020.

[2] J. Vrchota, P. Rehor, M. Marikova and M. Pech, "Critical success factors of the project management in relation to industry 4.0 for sustainability of projects," Sustainability, vol. 13, no. 1, pp. 1-19, 2021.

[3] R. Muller and K. Jugdev, "Critical success factors in projects: Pinto, slevin and prescott-the elucidation of project success," Int. Journal of Managing Projects in Business, vol. 5, no. 4, pp. 757-775, 2012.

[4] K. A. Demir, "A survey on challenges of software project management," Software Engineering Research and Practice, vol. 2009, no. 1, pp. 579-585, 2009.

[5] C. Stylianou and A. S. Andreou, "Intelligent software project scheduling and team staffing with genetic algorithms," Artificial Intelligence Applications and Innovations. Berlin, Heidelberg, pp. 169-178, 2011.

[6] K. V. Vasantrao, "Understanding need of flexible software development approach using The Economic Model," in 3rd Int. Conf. on Electronics Computer Technology, Kanyakumari, India, pp. 240-243, 2011.

[7] I. Attarzadeh and S. H. Ow, "Project management practices: The criteria for success or failure," Communications of the IBIMA, United States, vol. 1, pp. 234-241, 2008.

[8] S. McConnell, Software Project Survival Guide. Redmond, Washington: Microsoft Press, pp. 1-285, 1997.

[9] A. Belout and C. Gauvreau, "Factors influencing project success: The impact of human resource management," Int. Journal of Project Management, vol. 22, no. 1, pp. 1-11, 2004.

[10] A. Belout, "Effects of human resource management on project effectiveness and success: Toward a new conceptual framework," Int. Journal of Project Management, vol. 16, no. 1, pp. 21-26, 1998.

[11] MI. T.Moh'd, A. T. Haroon and A. Elsheikh, "Software development projects: An investigation into the factors that affect software project success/failure in Jordanian firms," First Int. Conf. on the Applications of Digital Information and Web Technologies (ICADIWT), Ostrava, Czech Republic, pp. 246-251, 2008. 
[12] K. Jeet, N. Bhatia and R. S. Minhas, "A model for estimating the impact of low productivity on the schedule of a software development project," ACM SIGSOFT Software Engineering Notes, vol. 36, no. 4, pp. 1-6, 2011.

[13] M. Jin, "The Development of the Chinese ICT Industry and Japanese Firms' Offshoring: With a Focus on Dalian's Case," Innovative ICT Industrial Architecture in East Asia. Vol. 17. Tokyo, pp. 99-114, 2017.

[14] K. Dikert, M. Paasivaara and C. Lassenius, "Challenges and success factors for large-scale agile transformations: A systematic literature review," Journal of Systems and Software, vol. 119, no. 10, pp. 87-108, 2016.

[15] R. Popli and N. Chauhan, "Cost and effort estimation in agile software development," in Int. Conf. on Reliability Optimization and Information Technology (ICROIT), Faridabad, India, pp. 57-61, 2014.

[16] N. Cerpa and J. M. Verner, "Why did your project fail?," Communications of the ACM, vol. 52, no. 12, pp. 130134, 2009.

[17] S. Falahah, "Risk management assessment using SERIM method," Int. Conf. on e-Education, Entertainment and e-Management, vol. 6, no. 2, pp. 340-343, 2011.

[18] R. Berntsson-Svensson and A. Aurum, "Successful software project and products: An empirical investigation," in Proc. of the ACM/IEEE Int. Sym. on Empirical Software Engineering, New York, USA, pp. 144-153, 2006.

[19] K. Molokken and M. Jorgensen, "A review of software surveys on software effort estimation," in Int. Sym. on Empirical Software Engineering, Rome, Italy, pp. 223-230, 2003.

[20] T. Chow and D. B. Cao, "A survey study of critical success factors in agile software projects," Journal of Systems and Software, vol. 81, no. 6, pp. 961-971, 2008.

[21] D. Stankovic, V. Nikolic, M. Djordjevic and D. B. Cao, "A survey study of critical success factors in agile software projects in former Yugoslavia IT companies," Journal of Systems and Software, vol. 86, no. 6, pp. 1663-1678, 2013.

[22] J. Verner, J. Sampson and N. Cerpa, "What factors lead to software project failure?," in Second Int. Conf. on Research Challenges in Information Science, Marrakech, Morocco, pp. 71-80, 2008.

[23] M. Jorgensen and M. Shepperd, "A systematic review of software development cost estimation studies," IEEE Transactions on Software Engineering, vol. 33, no. 1, pp. 33-53, 2007.

[24] J. M. Verner, W. M. Evanco and N. Cerpa, "State of the practice: An exploratory analysis of schedule estimation and software project success prediction," Information and Software Technology, vol. 49, no. 2, pp. 181-193, 2007.

[25] A. Bia, R. Munoz and J. Gómez, "Estimating digitization costs in digital libraries using DiCoMo," in Int. Conf. on Theory and Practice of Digital Libraries, Berlin, Heidelberg, pp. 136-147, 2010.

[26] J. Debari, O. Mizuno, T. Kikuno, N. Kikuchi and M. Hirayama, "On deriving actions for improving cost overrun by applying association rule mining to industrial project repository," in Int. Conf. on Software Process, Berlin, Heidelberg, pp. 51-62, 2008.

[27] G. W. Cheung and R. B. Rensvold, "Evaluating goodness-of-fit indexes for testing measurement invariance," Structural Equation Modeling: A Multidisciplinary Journal, vol. 9, no. 2, pp. 233-255, 2002.

[28] T. Asparouhov and B. Muthén, "Advances in Bayesian model fit evaluation for structural equation models," Structural Equation Modeling: A Multidisciplinary Journal, vol. 28, no. 1, pp. 1-14, 2021. 